\title{
Imaginarios patrimoniales y práctica etnográfica: experiencias en gestión cultural en el Sudoeste de la Provincia de Buenos Aires, Argentina ${ }^{1}$
}

\section{Patrimonial Imaginaries and Ethnographic Practice: Cultural Management Experiences in the Southwest of Bueno Aires Province, Argentina}

\author{
Gonzalo IPARRAGUIRRE \\ Universidad de Buenos Aires (Argentina) \\ gonipa@gmail.com
}

Recibido: 15 de agosto de 2013

Aceptado: 22 de junio de 2014

\section{Resumen}

Se presenta un estudio etnográfico sobre imaginarios patrimoniales, gestión del patrimonio cultural y sus implicancias político-científicas en el sudoeste de la Provincia de Buenos Aires, Argentina. A partir de la experiencia personal de haber trabajado en gestión e investigación del patrimonio cultural entre 2006 y 2012, se analizan dos estudios de caso que permiten reflexionar sobre la práctica profesional antropológica, la gestión y administración del patrimonio por los diferentes actores intervinientes, y la construcción de conocimiento científico en base al análisis de imaginarios sociales. Asimismo, se discute la importancia de la práctica etnográfica y el diagnóstico de los diferentes imaginarios sociales, al momento de realizar estudios patrimoniales que involucren a la comunidad local, las autoridades políticas y la comunidad científica. Finalmente, se presentan lineamientos generales para la elaboración de un modelo de intervención.

Palabras clave: Patrimonio Cultural, Imaginarios Sociales, Práctica Etnográfica, Antropología de Políticas Públicas.

\begin{abstract}
In the following article I present an ethnographic study of patrimonial imaginaries, cultural heritage management and its scientific-political implications in the southwest of the province of Buenos Aires, Argentina. From my personal experience as a technician in management and research of cultural heritage between 2006 and 2012, I analyze two case studies that will allow us to think about the anthropological practice, the heritage management by different actors, and the construction of scientific knowledge based on social imaginaries analysis. I also discuss the importance of the ethnographic practice and the diagnosis of different social
\end{abstract}

${ }^{1}$ Este artículo fue realizado en el marco de un Proyecto de Doctorado financiado con beca de CONICET (Comisión Nacional de Investigaciones Científicas y Tecnológicas), Argentina. Agradezco a los revisores los comentarios que favorecieron profundizar el trabajo, así como las oportunas sugerencias bibliográficas. 
imaginaries when it comes to study heritage within the local community, the political authority, and the scientific community. Finally, I will provide a general guideline to elaborate a model of social intervention.

Keywords: Cultural Heritage; Social Imaginaries; Ethnographic Practice; Anthropology of Policy.

Referencia normalizada: Iparraguirre, G. (2014). Imaginarios patrimoniales y práctica etnográfica: experiencias en gestión cultural en el Sudoeste de la Provincia de Buenos Aires, Argentina. Revista de Antropología Social, 23, pp. 209-235.

SUMARIO: 1. Introducción. 2. Enfoque teórico-metodológico. 3. Caso I: Recursos culturales en un área protegida. 4. Caso II: Gestión del patrimonio arqueológico y paleontológico. 5. Etnografía de imaginarios. 6. Modelo de intervención. 7. Referencias bibliográficas.

\section{Introducción}

Capitalizando la experiencia personal de haber trabajado en gestión del patrimonio cultural durante los últimos siete años, se propone analizar dos estudios de caso que propicien la reflexión, entre la práctica etnográfica del trabajo de campo y el trabajo profesional-laboral de los antropólogos en relación a la gestión de este patrimonio. Los ejes de reflexión e interrogantes en torno a los cuales gira el trabajo son: ¿De qué modo el patrimonio cultural permite pensar al territorio y sus diferentes valoraciones, manifestadas en los imaginarios que tienen los pobladores de un territorio? ¿De qué modo es factible traducir estas valoraciones del patrimonio en prácticas de investigación, manejo y acción sobre el territorio? ¿Cómo se accede a las representaciones sobre los componentes del patrimonio cultural que tienen los grupos sociales para elaborar políticas de manejo eficientes? ¿De qué modo es posible intervenir en el manejo de un mismo patrimonio cultural que hacen diferentes grupos sociales?

En esta dirección, se propone recopilar diversas experiencias de gestión cultural en el territorio, que manifiesten datos concretos para dar respuesta a estos interrogantes y analizar de qué modo se puede teorizar sobre el tema. A su vez, se busca generar herramientas conceptuales y metodológicas que puedan trasladarse a otros casos o regiones, y permitan planificar prácticas eficientes de gestión. El territorio en estudio se denomina geográfica y políticamente "Sudoeste de la Provincia de Buenos Aires", y en su interior pueden hallarse otras territorialidades específicas como las "Sierras de Ventania", la "Comarca Turística Sierras de la Ventana" y los once distritos que lo conforman (Figura 1).

La estructura del texto presenta en primer lugar, el enfoque teórico y metodológico utilizado para relevar, sistematizar e interpretar los imaginarios sociales en ambos casos etnográficos. Para la toma de datos en terreno se trabajó principalmente en base a una observación participante cotidiana en los diferentes sitios de campo (oficinas, senderos interpretativos, sitios arqueológicos, etc.) y se hicieron entrevistas dirigidas y semi-dirigidas a personas correspondientes a cada uno de los grupos identificados. 
Le sigue la descripción y análisis de ambas experiencias, haciendo hincapié en la intrínseca relación entre gestión e investigación del patrimonio a partir de la práctica laboral. El primer caso se centra en un área natural protegida y administrada por el Gobierno Provincial, donde tuve la oportunidad de trabajar e investigar entre los años 2006 y 2010. El segundo caso condensa la experiencia de trabajar durante tres años (2008-2010), en un Organismo Provincial sobre gestión del patrimonio arqueológico y paleontológico. Cierra el artículo una discusión crítica sobre el manejo político y científico del patrimonio cultural y como este puede ser analizado desde esta mirada atenta a los imaginarios. Este planteo es plasmado en un esquema que sintetiza los procesos de relevamiento, sistematización y toma de decisiones, factible de ser utilizado como herramienta de intervención en el manejo del patrimonio cultural.

\section{Enfoque teórico-metodológico}

Este trabajo se orienta al estudio de imaginarios sobre el patrimonio, o imaginarios patrimoniales, de acuerdo al presupuesto conceptual sobre el enraizamiento de toda práctica o hecho social en un imaginario. Centrado en la perspectiva antropológica sociocultural del patrimonio, se subraya la importancia de entender al patrimonio como construcción social, que no existe en la naturaleza como algo dado, que no es un fenómeno social universal, y que es históricamente cambiante (Prats, 2004). También se recupera la conceptualización de los usos sociales del patrimonio (García Canclini, 1999), así como las reflexiones en torno a las políticas culturales y patrimoniales (García Canclini, 2008; Santamarina Campos, 2013). En cuanto a la tradición antropológica en torno a "los imaginarios", esta se remonta a los estudios de sistemas simbólicos formulados por Durkheim (1982), Mauss (1979), Hubert (1990), Boas (1964) y posteriormente desarrollada por autores como Lévi-Strauss (1984), Castoriadis (1999), Appadurai (2001), Durand (2000; 2003; 2004), Baczko (2005), García Canclini (2008), Ricoeur (2012), Wright y Ceriani Cernadas (2007) y Wunenburger (2008), entre otros. Este presupuesto se apoya también en la teoría de campos simbólicos formulada por Bourdieu (2008), respecto a la cual, se asocia aquí que los imaginarios patrimoniales pueden interpretarse simultáneamente como campos patrimoniales, constituidos de otros campos simbólicos y sus respectivos espacios sociales, como el científico, el político, el económico o el jurídico.

Se define aquí a los imaginarios sociales como conjuntos de representaciones mentales y materiales sobre los modos de pensar y actuar de un grupo social en su vida cotidiana. Esta definición se construye en base a los estudios sobre antropología del imaginario, formulados por varios de los autores citados, y sintetizados recientemente por Jean-Jacques Wunenburger, quien resume así los criterios de análisis centrales para un estudio sistemático:

Solo hay imaginario si un conjunto de imágenes y relatos forma una totalidad más o menos coherente, que produce un sentido distinto del local y momentáneo. Lo imaginario está del lado de lo "holístico" (totalidad) y no "atomístico" (elemento). Lo imaginario puede ser descrito literalmente (temas, motivos, intrigas, ambiente), pero también dar lugar a interpretaciones, dado que las imágenes y los relatos son, en general, portadores de un segundo sentido indirecto [...] los diversos constituyentes 
de un imaginario (tiempo, personaje, espacio, acción, etc.) pueden dar, luego de una interpretación, indicaciones preciosas sobre el sujeto que imagina, que emplea estos operadores para expresar afectos, ideas, valores. Entonces, el estudio de lo imaginario como mundo de representaciones complejas debe tener por objeto el sistema de imágenes-texto, su dinámica creadora y su pregnancia semántica, que hacen posible una interpretación indefinida, y, por último, su eficacia práctica y su participación en la vida individual y colectiva (Wunenburger, 2008: 16).

Asimismo, como lo explican los antropólogos Wright y Ceriani Cernadas, los símbolos, al ser asociados de diversos modos, generan imaginarios:

En la actualidad esta expresión parece reemplazar, en muchos contextos, a lo que antes se denominaba cultura ofreciendo una plasticidad, variabilidad y evanescencia analíticas de mayor alcance. Así nos encontramos con la imaginación social, la histórica; los imaginarios urbanos, espaciales, de clase, etc. que permiten mayor espacio de maniobra analítico a la episteme de las ciencias sociales y las humanidades (Wright y Ceriani Cernadas, 2007: 320).

No se trata de agrupar "opiniones" o "percepciones" de sujetos o grupos sociales que limitan la interpretación al campo discursivo. Sin desconocer la relevancia de los componentes discursivos y afectivos, los imaginarios integran tanto a las opiniones como a las percepciones en un sistema de significación que conecta a los interlocutores con los procesos históricos que perfilan su imaginación contextualizada y sus correlativas prácticas cotidianas. La importancia de reconocer y analizar a los imaginarios como construcciones culturales dinámicas e históricas reside en el valor descriptivo y diagnóstico que tienen sobre los grupos humanos, en particular para entender comportamientos individuales y grupales, hábitos colectivos, modos de producción y ritmos de vida. El trabajo se enfoca a tres conjuntos específicos de imaginarios, patrimoniales, científicos y políticos, — dando una mayor relevancia al primero por motivos de extensión del artículo_-, para acceder y esclarecer de forma sistemática y fundamentada, a qué representaciones se refieren los grupos sociales analizados en los casos de estudio, cuando en sus discursos y en sus imágenes-texto, se manifiestan categorías específicas como: patrimonio, recursos, cultura, naturaleza, territorio, desarrollo, difusión, conservación, investigación, ciencia, poder, y otros de similar relevancia.

Los conflictos en la interpretación de los recursos culturales y naturales, así como los usos del territorio asignados a espacios patrimoniales que existen entre diferentes actores vinculados a los mismos, se traducen desde el enfoque antropológico, en un conflicto semiótico y práctico a la vez; de lenguaje, comunicación y acción, donde lo que se pone en juego en toda práctica técnica y/o política son las representaciones simbólicas de cada actor, las cuales están construidas históricamente, y en contextos sociales cambiantes. Es en este nivel comunicativo-performativo donde se encuentran los puntos de contacto entre esos diferentes lenguajes que emergen en los distintos discursos-imágenes, ya sea en reuniones técnicas y académicas entre investigadores, eventos políticos, actividades de gestión, exhibiciones, museos, y otros actos de intervención multisectorial, y por lo tanto, con fuertes componentes multiculturales. 
La metodología implementada para analizar los imaginarios propone enmarcar los estudios de caso como campos etnográficos conformados por grupos sociales posicionados en el territorio. La noción de "campo etnográfico" combina el concepto de campo simbólico formulado por Bourdieu (2008), y conceptualizaciones sobre las prácticas espaciales en torno al trabajo etnográfico (Clifford, 1999; De Certeau, 1984; Wright, 2005, 2012). Los grupos sociales se definen como el conjunto de actores sociales que interactúan al interior del campo etnográfico en estudio, activando relaciones de poder y demarcando posiciones socioculturales en el territorio. A su vez, los imaginarios de cada grupo identificado se analizan siguiendo una matriz interpretativa estructurada en base a los trabajos de Durand (2000; 2003; 2004) y Wunenburger (2008). Esta consiste en un sistema de análisis de imaginarios organizado por niveles jerárquicos inclusivos: constelación-componente-categoría. Se mantiene la noción de "constelación" de Durand como categoría de mayor amplitud de significación, y se asigna a "componente" lo formulado por el autor para esquema y estructura (Durand, 2004: 442-443). "Categoría" sintetiza aquí el plano de los símbolos y conjuntos de representaciones asociados al lenguaje que emergen del diálogo cotidiano con los interlocutores. Se considera al nivel más general en términos de "constelaciones" ya que, como enfatiza Wunenburger, "los abordajes más innovadores de lo imaginario se orientan hacia la identificación de constelaciones coherentes que revelan su capacidad de auto-organización de las ideas, afectos y acciones de los agentes que lo vehiculizan" (Wunenburger, 2008: 59).

Ambos campos etnográficos fueron analizados en base a tres constelaciones específicas de imaginarios: "patrimonio", "ciencia" y "política". Los componentes simbólicos de cada una de estas constelaciones fueron trazadas durante el trabajo de campo, en base a la emergencia de las categorías constituyentes de imaginarios en la mayoría de los registros, y en base a posteriores reformulaciones que el análisis permitió visualizar con mayor claridad. De este modo, la constelación de imaginarios patrimoniales se compone de "identidad", "recursos culturales" y "recursos naturales". Las categorías para el componente "identidad" son: tradición, familia, costumbres, transmisión de saberes. Para el componente "recursos culturales" las categorias son: producciones humanas tangibles e intangibles, conservación. Para el componente "recursos naturales" las categorías son: biomas, flora y fauna (nativa y exótica), biodiversidad. Esta tensión entre los componentes "naturaleza" y "cultura" para clasificar a los recursos, se puntualiza de modo complementario, ya que la posición simbólica de una es definitoria de la otra por diametral oposición. Se registró en el conjunto de las entrevistas - ya fueran con los biólogos, los guardaparques, los guías de turismo y el conjunto de los turistas-, la referencia a un objeto como "cultural" si no es natural, y "lo natural" como aquello que no es cultural. Lo natural es asociado a "bioma", "flora", "fauna", "biodiversidad" y se trasluce en imágenes encontradas, como la dualidad "nativo-exótico", "auténtico-intervenido", "impoluto-contaminado". Lo cultural se asocia a la actividad humana en general, destacándose "lo indígena", lo "arquitectónico", "costumbres y creencias", la "agricultura", lo "agropecuario" y toda modificación del paisaje geográfico, toda alteración del bioma que debería haber sin la intervención humana. Esta polarización 
manifiesta, entre los interlocutores del Área Protegida Natural como entre los funcionarios, tiene sus raíces históricas y epistemológicas en la modernidad:

La concepción de los espacios naturales, deudora del pensamiento decimonónico, se cimienta en la propia construcción occidental que establece como dominios independientes — dicotómicos y diferenciados — la naturaleza y la cultura [...] Y, quizás, la expresión "parque natural" sintetiza la contradicción que implica esta división de mundos y es reveladora de la manera en que hemos dibujado históricamente el concepto de naturaleza como dominio externo (Santamarina Campos, 2012: 27).

Asimismo, como ya se ha formulado desde la antropología simétrica (Latour, 2007), y particularmente con aplicación a estudios de arqueología (GonzálezRuibal, 2007), resulta de mayor precisión epistemológica hablar de naturalezasculturas para trabajar los híbridos de "cuasi-objetos" "cuasi-humanos" como las que manifiestan las imágenes-textos recién mencionadas: "los hechos científicos están construidos pero no pueden reducirse a lo social porque éste se puebla de objetos movilizados para construirlo" (Latour, 2007: 22). Al disociarse los objetos-cosas que identifican al patrimonio de los sujetos que los movilizan y los resignifican en sus interpretaciones y manejo, se establecen relaciones asimétricas que reproducen la polarización entre el "saber experto" y el "saber aficionado". Precisamente, la constelación "ciencia" tiene una posición simbólica legitimante en cuanto a que debería ser o no patrimonio, dependiendo de la voz que lo reconozca como tal, con mayor o menor "status científico", y según se posicione más allá de lo estrictamente natural o más acá de lo evidentemente cultural.

La constelación de imaginarios científicos tiene como componentes recurrentes: "investigación", "educación" y "conocimiento". Las categorías principales del componente "investigación" son: ideas de lo científico, legitimidad de los discursos, criterios de verdad. Para el componente "educación" se destacan: divulgación, difusión, extensión. Y para "conocimiento" las categorías son: saberes, formación, capacitación. Los diferentes modos de expresión del imaginario científico en el patrimonio cultural, se manifiestan en las prácticas de investigación —condensadas principalmente en el campo académico-, en las educativas (relegadas al ámbito pedagógico o de transferencia informal), y en la generación de "conocimiento patrimonial" en general, que suele reproducirse en tanto en los ámbitos académicos de extensión (congresos y jornadas) como en los medios periodísticos.

En cuanto a la constelación de imaginarios políticos, pueden distinguirse al menos tres componentes, que por supuesto pueden superponerse con algunos de los ya mencionados: "territorio", "Estado" y "desarrollo". Las categorías para el primero son: entornos y ámbitos naturales-culturales, paisajes, territorios turísticos. Para "Estado" las categorías típicas son: las intervenciones a nivel municipal, provincial, nacional e internacional; así como las tensiones entre sectores públicos y privados. Para "desarrollo", se destacan: los usos turísticos, científicos y educativos de los recursos. La superposición de significados se visualiza claramente en la noción de "paisaje", ya que incluye la simetría entre naturaleza y cultura que se distingue entre los recursos naturales y culturales, sobre todo al asociarse a territorios 
turísticos —paisaje pintoresco, lindo paisaje—; o a ámbitos productivos, como el paisaje de un maizal o el paisaje del ganado en el campo. En su dimensión política, el territorio en clave patrimonial, se complementa con las intervenciones del Estado - legislaciones, normativas, procedimientos de rescate y manejo-, y las representaciones del desarrollo que implican el uso del patrimonio, ya sea como recurso turístico, científico o educativo.

En este sentido, puede definirse un imaginario patrimonial, como el conjunto de representaciones simbólicas sobre "el patrimonio" que un grupo social comparte en base a la articulación de componentes y categorías. Estos componentes simbólicos, agrupan a los recurrentes significados que los agentes sociales atribuyen a las categorías utilizadas para interpretar e interactuar con el patrimonio. Lo propio puede aplicarse para definir a los imaginarios científicos, al agrupar representaciones simbólicas sobre "la ciencia", y a los imaginarios políticos, al agrupar representaciones simbólicas sobre "la política". Introducido el enfoque teórico-metodológico, se enfatiza que el objetivo general del trabajo es analizar los dos casos que a continuación se presentan, desde una perspectiva etnográfica centrada en los imaginarios patrimoniales, políticos y científicos, con el propósito de discutir la importancia del método etnográfico para el acercamiento a este entramado de representaciones sociales, campos simbólicos y manejo político-científico del patrimonio.

\section{Caso I: Recursos culturales en un área protegida}

Mi primera experiencia como investigador en torno al patrimonio cultural fue la realización de una investigación sobre el manejo de recursos culturales en el Parque Provincial Ernesto Tornquist (en adelante PPET) (Figura 1). Este parque se ubica en el Sistema Serrano de Ventania, partido de Tornquist, Argentina, y tiene una extensión de 6.700 hectáreas. Fundado en 1937, su misión principal es la conservación del patrimonio natural, lo cual incluye su patrimonio geológico y paleontológico, el ecosistema de pastizales pampeanos, cuencas hídricas y arroyos —afluentes del Río Sauce Grande, principal fuente de abastecimiento de agua potable para Bahía Blanca. Desde 1997 también se incorporó la protección de los recursos históricos y arqueológicos, tangibles e intangibles, que componen su patrimonio cultural (Iparraguirre, 2011).

Durante el año 2006 se hizo el primer trabajo de campo orientado a relevar los recursos culturales conocidos y registrar los nuevos. Los relevamientos consistieron en registrar recursos tangibles e intangibles, compilación de bibliografía, documentos de archivo, fotografías, recortes periodísticos, y entrevistas dirigidas y semi-dirigidas al personal del parque, a investigadores y a turistas. Este informe técnico fue presentado y discutido entre las autoridades del parque y su personal operativo, quedando finalmente como propuesta de un Plan de Manejo de Recursos Culturales (Iparraguirre, 2007). Esta propuesta de manejo se basó en el Plan de Manejo Formal, aún vigente en el PPET (Fiori, Scorolli y Zalba, 1997), el cual centra su atención en los recursos naturales del Parque, destacando las consideraciones biológicas y medioambientales.

Sin dejar de lado descripciones "típicas" del formato de un plan de manejo para un área protegida, el informe realizado contaba con la siguiente estructura: 


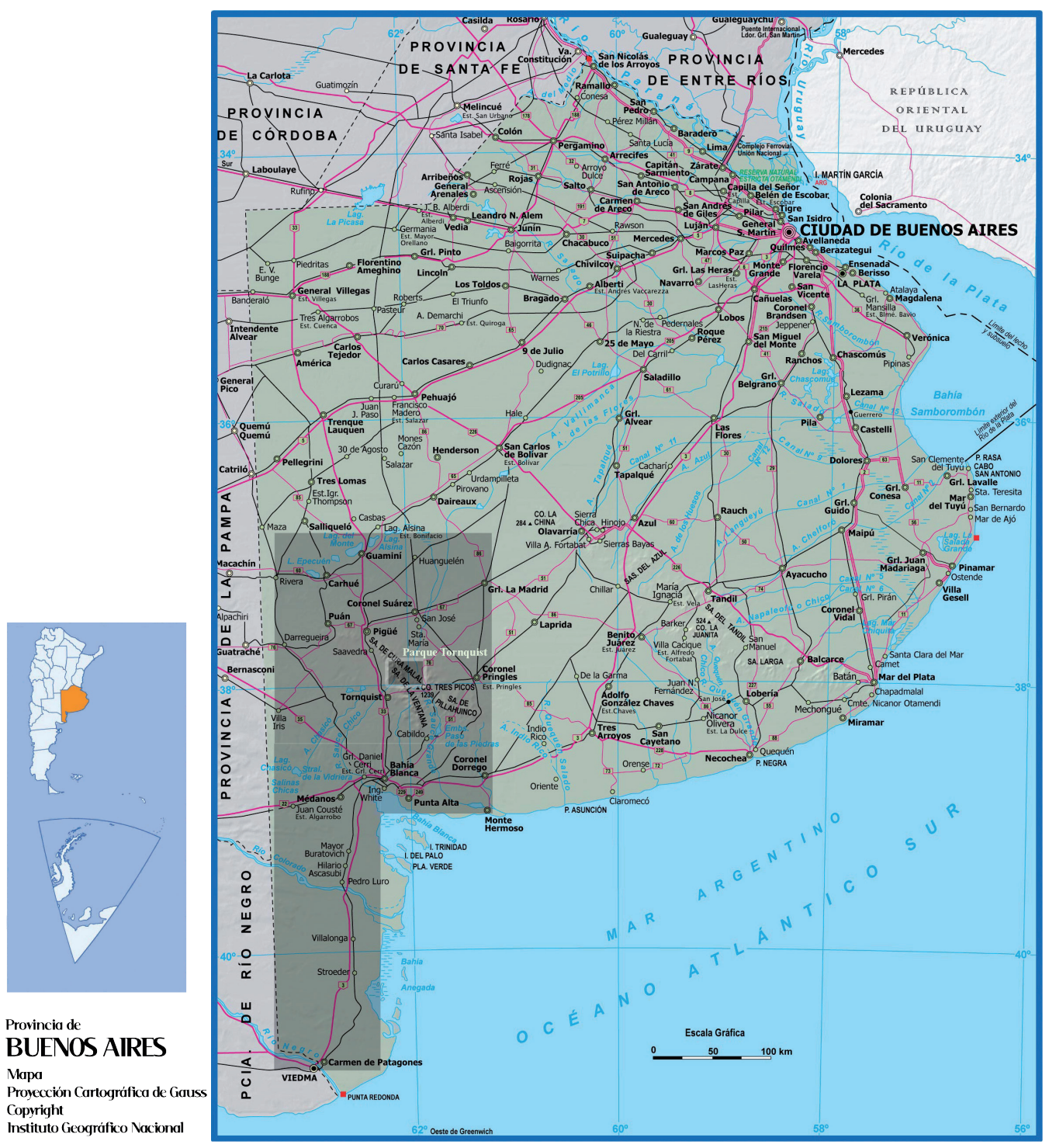

Figura 1. Mapa de la región de estudio con ubicación del Parque Tornquist. Fuente: Instituto Geográfico Nacional de Argentina, modificado por el autor. 
definiciones y antecedentes, caracterización del PPET, consideraciones medioambientales, consideraciones antropológicas, consideraciones de conservación, consideraciones de divulgación e investigación y propuestas de manejo. Este esquema conceptual incorporaba, desde la mirada sociocultural, las consideraciones antropológicas y las pautas para divulgación e investigación; acciones consideradas como recursos culturales intangibles para la toma de decisiones operativas. Todo ello se dio en el contexto de una tendencia en nuestro país de dar continuidad a los estudios sobre recursos naturales y sus implicancias legales al momento de trabajar sobre paisajes, integrando los componentes culturales en términos de "recursos". En Argentina, una de las instituciones pioneras en este sentido fue la Administración de Parques Nacionales, organismo nacional del manejo y protección de las áreas naturales (Molinari, 1998; 2000). Como bien lo explica la arqueóloga María Luz Endere:

El concepto de recursos culturales se inspira en la noción de recursos naturales, ya que se trata de recursos limitados, no renovables, diseminados en el paisaje, que son de interés público y que deben ser protegidos por la legislación de patrimonio, así como contemplados en la normativa de planificación territorial (Carta de ICOMOS para la gestión del Patrimonio Arqueológico de 1990). Este concepto dio paso a una nueva especialidad denominada "manejo o gestión de los recursos culturales" (Endere, 2009: 19).

En efecto, el Plan de Manejo de 1997 se explaya exhaustivamente sobre la conservación de la flora y fauna nativas, el manejo del fuego en los pastizales, describe las formaciones geológicas y cuencas hídricas, pero dedica solo una página a los recursos culturales, mencionando brevemente los registros arqueológicos conocidos (cuevas con arte rupestre y material lítico), sin mencionar ningún otro recurso histórico-cultural, evidenciando — al menos desde la construcción discursiva - la ausencia del componente cultural en el imaginario patrimonial de quienes coordinaron la elaboración del mismo.

Advertida esta tendencia entre los interlocutores hacia una mirada centrada en los recursos naturales, el trabajo de campo se enfocó a relevar y sistematizar la profundidad histórica y cultural del parque así como a las diferentes sociedades que lo transitaron y transitan, para revertir esa ausencia notoria de "rasgos" culturales. La mirada de los actores entrevistados reproducía el discurso de "lo arqueológico y los edificios" como dato primario de "lo cultural", tal como había quedado instaurado en el Plan de 1997 recién citado. Aunque resulten a veces imperceptibles, las omisiones en un relato pueden consolidar imaginarios completos desde lo ausente: - "acá solo tenés cuevas con pinturas rupestres y algunas puntas de flechas, nunca se encontró más que eso", respondió uno de los guías del Parque en una de las conversaciones iniciales-; "se supone que las hicieron los mapuches o los tehuelches, no está muy claro el dato, algunos dicen hace 1.500 años, otros más, los arqueólogos no se ponen de acuerdo", completó otro guía, dándome un panorama de la incertidumbre respecto al pasado indígena.

En esta dirección, la descripción que realicé de los recursos distinguía en principio la diferencia entre lo tangible y lo intangible: 
Los recursos tangibles en el Parque Tornquist se pueden agrupar en: recursos edilicios (construcciones inmuebles y muebles), registros arqueológicos (elementos de molienda, puntas de flecha, material lítico en general, corrales realizados con pircas de piedra, cuevas con arte rupestre) y otro grupo de instrumentos al que podemos denominar recursos didácticos (material educativo, de exposición, etc.). Entre los principales recursos edilicios podemos mencionar, en el sector del Cerro Bahía Blanca: al Ex Hotel Provincial (en ruinas), la actual sala de interpretación y residencia de guías e investigadores, la oficina administrativa, el vivero forestal, los fogones de uso público, el Jardín Botánico Pillahuincó, el sismógrafo, un refugio de montaña, las casas de guardaparques y demás personal residente al interior del Parque. En el sector del Cerro Ventana se encuentran: dos estaciones de radio en su cima, una sala de recepción, una casa de guardaparque y el campamento base (camping concesionado por el Municipio). En el sector La Toma se ubica, además de la casa de otro guardaparque, una antigua construcción del Ex Club Hotel de la Ventana donde hoy funciona la bomba de agua de Villa Ventana (Iparraguirre, 2007: 44).

Esta enumeración seguía los criterios de quienes me orientaban en la búsqueda de los rastros de actividad humana, aún bajo la previa aclaración de que no hacía falta la distinción de períodos históricos, ya que la tendencia era a hablar solo de registros arqueológicos - referido a grupos indígenas erradicados durante la colonización - y nadie nombraba recursos históricos, o conocimientos relacionados a grupos indígenas actuales, o a los mismos pobladores que hoy habitan la región. El imaginario patrimonial que emergía del trabajo de campo con los interlocutores era claramente de una temporalidad finalizada, anclada en "lo antiguo" y "lo ancestral", y definitivamente terminada, sin implicancias en el devenir de la población actual. De hecho, este aspecto parecía ser un criterio de distinción entre el recurso natural, todavía presente y vivo, y el recurso cultural, muerto y perdido en el pasado.

En cuanto a los recursos intangibles, el informe describía:

Los recursos intangibles permiten un acceso al conocimiento de los diferentes grupos sociales que habitaron y habitan la región. En principio se puede distinguir entre los recursos que los mismos pobladores han creado (mitos y relatos en relación a las representaciones rupestres, leyendas) y por otro lado a las fuentes (recursos históricos) que sobre estos pobladores se han creado luego de la colonización y también sobre ellos mismos hasta la actualidad, ya sea por transmisión oral o escrita, como vimos en las consideraciones antropológicas. Me refiero aquí a las representaciones rupestres también como recurso intangible en tanto si pensamos las pinturas como 'archivo simbólico' de discursos con sentido (mensajes) entonces el material arqueológico es también la fuente de conocimiento que indistintamente de la interpretación que se realice transmite cierta información sobre su creador. La distinción entre tangible e intangible tiene sus limitaciones y en estos casos se torna evidente. No obstante, es útil al momento de ordenar la información disponible e intentar sistematizarla (Iparraguirre, 2007: 45).

Estas descripciones pretendían esbozar mínimamente un planteo sobre la trascendencia de recuperar aspectos intangibles de un imaginario cultural invisible que hasta entonces resultaba inexistente, como si nada hubiese pasado salvo aquello que podemos constatar con nuestra vista. 
Otra imagen-texto relevante de la concepción de "lo cultural" entre el personal del parque y las autoridades de áreas protegidas de ese momento, que está presente en el Plan de Manejo de 1997, es la mención en el organigrama a un área específica de trabajo llamada "Encargado del manejo de recursos culturales". Este puesto nunca se cubrió durante los 10 años que separaban el Plan de Manejo citado y mi informe técnico —entre 1997 y 2007 - mientras que el resto de las áreas se cubrieron o se redefinieron con personal a cargo, a veces con superposiciones de hasta 2 o 3 funciones a la vez, sin que nadie se encargara de "lo cultural". Tal es así, que cuando yo expliqué en una de las entrevistas al guardaparque a cargo mi interés en continuar el estudio de los recursos culturales en el Parque, me comentó: - "sería bueno tener este estudio que estás haciendo para ver como encaramos el tema, no sabemos por dónde empezar a tratarlo, sabemos que es necesario, pero no tenemos personal que lo pueda hacer".

De este modo surge mi segunda experiencia de trabajo en el Parque, a partir de la propuesta de realizar una asesoría en manejo de recursos culturales para poner en marcha lo planteado en el Plan de 1997 — que nunca se activó — y en el reciente informe técnico que había realizado. La principal actividad durante esta asesoría se centró en escribir y diagramar un guion museográfico destinado al rediseño y refacción de la sala de interpretación, realizada por investigadores de la Universidad Nacional de La Plata en 1983. La diagramación de los contenidos de este guion, contó deliberadamente con la contraposición complementaria de ambas posturas, cultural y natural, aunque en ese momento yo no tenía en claro a qué respondía tal polarización. El guión se fue escribiendo al compilar información de primera mano junto a investigadores — biólogos, agrónomos y geólogos - y bajo la supervisión del personal de guías de turismo y guardaparques, quienes contaban con la experiencia de interactuar con los visitantes y conocer sus intereses y preguntas más frecuentes.

Una vez finalizado el escrito se comenzó a gestionar los recursos para su implementación en paneles museográficos y un posible rediseño del edificio. Luego de varias idas y venidas, reuniones con funcionarios provinciales, pedidos de presupuestos y reuniones con el personal del área para pulir el guión y el enfoque de la flamante sala de interpretación, el dinero requerido nunca se aprobó. Durante los años siguientes hubo otros intentos de reactivar el proyecto, e incluso en 2010 se realizó un taller de interpretación financiado por el organismo provincial que regula las áreas protegidas en la Provincia, para redefinir los mensajes centrales y los lineamientos museológicos de la sala de interpretación. A pesar del trabajo colectivo - $\mathrm{y}$ ad honorem - de todos los participantes para sistematizar la información elaborada durante el taller, tampoco se llegó a concretar la etapa constructiva por la ausencia de los fondos.

En conclusión, en este primer caso de estudio es factible observar la influencia decisiva de los imaginarios patrimoniales de los actores, centrados inicialmente en los recursos naturales, al momento de la toma de decisiones políticas. Por un lado no sostuvieron los estudios antropológicos sistemáticos en el área, y por el otro, no otorgaron fondos para la implementación de los estudios de manejo y para el guion museográfico realizado. Esta imagen de lo cultural subsumido en lo natural responde 
también a constricciones específicas del campo científico (Bourdieu, 2008) en el que se han formado la mayoría de los guardaparques de nuestro país, bajo un diseño curricular centrado en la preservación de la flora y la fauna sin considerar las variables socio-históricas que intervienen en los diferentes ambientes y paisajes culturales, ahora "protegidos" por el manto legal que suponen las leyes de parques, bosques, etc. Asimismo, fue notorio el desconocimiento por parte de todos los interlocutores entrevistados, de las convenciones internacionales relativas al patrimonio cultural que podrían haber sido aplicadas a la pueda en valor y manejo de los recursos presentes en el área (UNESCO, 1972, 2003, 2006; ICOMOS, 1990, 1999, 2005; OEA, 1976).

En este sentido, puede sostenerse que el fracaso o inviabilidad de estas intervenciones responde, en parte, a que todos los actores intervinientes teníamos una "idea de lo cultural" subsumida a la praxis política de "lo urgente" en términos de rédito popular y a la supuesta prioridad "de lo natural". El imaginario de estos actores evidenciaba un comportamiento pasivo ante la no-gestión por parte de los funcionarios, como si fuera obvio que los políticos no iban a destinar fondos para "algo cultural" cuando sus intereses estaban puestos en otras acciones "más urgentes": persistencia en los cargos, desviación de fondos, clientelismo, entre otros. Como ejemplo de contraste, se puede plantear que a ninguno de los actores interesados en el "desarrollo cultural" del PPET se le ocurrió ir a cortar la calle frente al Ministerio de Asuntos Agrarios en La Plata — organismo del que dependía entonces el Parque - para reclamar el otorgamiento de fondos a estos temas prioritarios para el "crecimiento sociocultural" de la región. Podría sonar irrisorio pensar en un corte de calle, o un cese de actividades como reclamo de fondos para rediseñar una sala de interpretación, o para crear un sendero interpretativo de la historia indígena y criolla de Ventania. Pero el dilema es si realmente es una postura descentrada de los problemas "verdaderos" o si se trata de una falta de integración del imaginario histórico y social a la "realidad" cotidiana de los pobladores locales. Si todos somos conscientes de la relevancia cultural y educativa de la implementación de recursos culturales educativos, de la llegada a miles de personas que puede tener en un Parque Provincial, ¿porque no se imagina el reclamo de "lo cultural" como un valor social y popular de equivalente significación a reclamos "de urgencia social"?

Aquí se evidencian los dilemas que emergen de un estudio sistemático de los imaginarios sociales, cuando la profundidad llega a tocar fibras enraizadas en procesos sedimentados en las instituciones, en hábitos sociales e historizados, construidos "lentamente" y de forma "imperceptible" para la velocidad del ritmo de vida globalizado que hoy transitamos.

\section{Caso II: Gestión del patrimonio arqueológico y paleontológico}

El segundo caso de estudio se enfoca a la gestión del patrimonio arqueológico y paleontológico por parte de un Observatorio Provincial de Patrimonio. Entre 2008 y 2010 trabajé para la Dirección Provincial de Patrimonio Cultural del Instituto Cultural de la Provincia de Buenos Aires, a partir del ofrecimiento de coordinar una sede del Centro de Registro de Patrimonio Arqueológico y Paleontológico en la región del sistema de Ventania. Esta región comprendió en su primer formato, entre 2008 
y 2009, los partidos de: Tornquist, Saavedra, Pringles, Suarez, A. Alsina, Guamini, Puan y Villarino (Figura 1). Esta sede se denominó Observatorio de Patrimonio Arqueológico y Paleontológico (OPAP N ${ }^{\mathrm{o}}$ 1). En 2010 se redujo la cantidad de distritos a la mitad, y posteriormente a mi cese, se desarticuló el Observatorio y se creó un representante local en el territorio.

En teoría, el propósito de este Observatorio era generar vínculos estrechos con las comunidades locales para que "de este modo se terminará con la desarticulación y las barreras que muchas veces dificultan la realización de las actividades de protección, investigación, difusión y transferencia del patrimonio cultural" (Iparraguirre et al., 2010: 482). Algunas de las funciones previstas desde sus documentos fundacionales eran: "Coordinar políticas educacionales y de difusión masiva de la Ley Nacional $\mathrm{N}^{\mathrm{o}} 25.743$ [...] Identificar agentes de deterioro de sitios arqueológicos y yacimientos paleontológicos [...] Fortalecer la identidad y conciencia regional [...] Controlar el saqueo, destrucción y tráfico ilegal" (Iparraguirre et al., 2010: 484). Aunque son múltiples los aspectos de esta experiencia de gestión patrimonial que pueden aplicarse a este trabajo, me limito aquí a describir situaciones que dan cuenta de la permanente tensión entre los imaginarios patrimoniales y los científicos, emergentes en la confrontación de intereses, discursos y prácticas.

Inicialmente, la propia práctica de crear este observatorio como un "satélite" de la oficina central en la ciudad de La Plata — capital de la Provincia de Buenos Airesy sostenerlo desde una oficina virtual como era mi persona, la computadora y mi auto, y también desde una oficina transitoria —el espacio brindado por el Parque Tornquist para recibir gente-, generó una transformación radical del modo previsto de trabajar y de articular con personas e instituciones. El imaginario patrimonial que se debía construir como oficina de asuntos patrimoniales no lograba adquirir ese estatus, ya que no se implementaban las condiciones mínimas para fomentar un espacio concreto donde se pudiera trabajar de forma directa con los interlocutores interesados. Esto conllevó indefectiblemente a construir una imagen-texto del Observatorio basada en la movilidad del personal técnico hacia los recursos y las personas, en continuo movimiento y sin asidero en referencias precisas que ubicaran las imágenes de gestión patrimonial que se pretendían consolidar desde los lineamientos políticos.

Bajo este contexto de representaciones, y con el objetivo de hacer relevamientos de colecciones municipales y privadas, durante los tres años de trabajo se hicieron varios viajes a los diferentes municipios, en general sin que estos demandaran la visita y con cierto escepticismo sobre la relevancia de la temática. Las visitas protocolares se hacían principalmente a las Direcciones de Cultura de los Municipios, áreas "predestinadas" a lidiar con las "rarezas culturales" que no logran cuadrar en áreas municipales más específicas y "transparentes”, como Producción, Obras Públicas, Medio Ambiente hasta incluso Turismo, aunque en la mayoría de los municipios mencionados Cultura y Turismo conforman la misma área de "incertidumbre". Merecería un trato especial reflexionar sobre la falta de forma, y el consecuente vacio de sentido que esto genera, de las áreas municipales de cultura y sus componentes artísticos, políticos y económicos, pero esta problemática excede el propósito de este trabajo. 
La primera frase que un Director de Cultura menciona - si es que lo hay y no está siendo remplazado "interinamente" por cualquier otro funcionario-, luego de saludar cordialmente y ofrecer una taza de café es: - “como bien usted sabrá, esta dependencia no posee fondos para temáticas por las que usted seguramente nos visita". Esto condiciona desde un primer momento lo que uno pueda decir sobre esa "temática cultural incierta" que debería trabajar junto al funcionario encargado de administrar y gestionar todo lo relacionado al patrimonio cultural de la comuna que representa. En la mayoría de los 11 distritos que recorrí, los funcionarios no sabían bien de qué se trataba el tema "patrimonio cultural", por lo cual se "atajaban" de antemano, previendo desligarse de un problema que "no deberían" estar atendiendo.

El imaginario patrimonial en estos casos es evidentemente el del vacio patrimonial, centrado en actitudes de incertidumbre y de razonamientos de problemas ajenos. Este vacío se trasluce a través de los discursos y las prácticas del desmanejo, del desligamiento del tema en terceros, o en su negación. El patrimonio arqueológico y paleontológico debería, según esta visión, restringirse a los museos —si es que existen-, o a los aficionados que tienen esos hobbies de fin de semana y después no saben qué hacer con todas esas "piedras y huesos". Esta es una clara imagen de la realidad material del patrimonio arqueológico y paleontológico: piedras y huesos. Los discursos de los interlocutores repiten: - "¿a quienes le interesan esas cosas hoy, cuando vivimos en un mundo de tecnología y que lo importante es que llueva y los campos sean productivos? ¿Para qué andar buscando piedras y huesos en los campos, en las lagunas?". Los Directores de Cultura prefieren trasladar el problema a quienes deben oficiar como "lugares de guarda" o quienes se molestan en "seguir amontonando" piedras y huesos. Consideran que no son temas del área cultura, a lo sumo pueden serlo si se hace una muestra y se inaugura frente a los medios de prensa locales; se les otorga un lugar en algún rincón de los edificios municipales y no merecen mayores discusiones. Cultura, el Área, la Dirección, o la Secretaria debe ocuparse, según estos funcionarios que fui conociendo, de los eventos populares masivos o tradicionales, de las ferias de arte, de los concursos de pintura, de la organización de los actos oficiales con "temas históricos", por ejemplo en fechas patrias, o tributos a "próceres" locales (como si todo hecho social no lo fuera), de generar un archivo de diarios y notas de prensa donde se evidencie la acción del intendente de turno, entre otras actividades. Y si aparece algo "interesante", algo "nuevo o raro", como un fósil o un enterratorio, se activa otro campo semántico que se reduce a la fórmula del "vemos que hacer": - "vemos si amerita hacer algo nosotros o llamamos a los de La Plata, esos temas los manejan ellos"- me contestó el Director de un Museo Municipal. Luego agregó: - "las excavaciones, la investigación, las interpretaciones sobre este patrimonio solo se pueden hacer con especialistas que vienen de La Plata, nosotros acá no podemos hacerlo, no estamos capacitados, o no nos dejan hacerlo", evidenciando otro elemento clave de la construcción del imaginario patrimonial y científico entre los "funcionarios culturales" del sudoeste de la Provincia: la posición simbólica dominante del centro y la periferia. Traducido en el plano de la gestión cultural, se promueve una fórmula de ineficacia mutua, ya que desde la urbe se limita la acción de los locales a la par 
que se les informa de modo incompleto en el modo de operar frente a los hallazgos o la producción de conocimiento. Así se reproduce un modelo centralista de cómo se construye "la ciencia" y el conocimiento, un modelo laplatacentrista, que nunca dejó de operar, aun cuando se promoviera desde instancias como las de este mismo Observatorio, que era una tendencia a la descentralización. El poder se construye en La Plata y desde allí se administra qué objetos y qué contenidos "se bajan" a los funcionarios y museos locales. La estructura política verticalista se reproduce, desde las Direcciones Provinciales hacia las Secretarias y Direcciones de Cultura, aun cuando se lo quiera amalgamar o alivianar desde discursos que ofrecen una descentralización ficticia, teatralizada a través de los actores mediadores o intermediarios - como lo fue también mi caso.

La experiencia del Observatorio en este sentido, fue la de una legitimación indirecta de ese modelo centralista, aun cuando la intención era la de descentralizar las prácticas centralistas al poner un intermediario presente en el territorio local. En algún punto no deja de tener reminiscencias evangelizadoras o neocolonialistas esta posición política-científica, y así se fue construyendo la mirada de varios agentes sobre la postura del OPAP, o sobre mi función dentro de una estructura intrínsecamente contradictoria, con las políticas centralistas previas y con la supuesta acción de observación, registro y vínculo estrecho que se venía a proponer. El marco histórico de este proceso "La Plata-interior de la Provincia" tiene antecedentes precisos en la intervención de varios arqueólogos que reprodujeron este sistema, y que en algunos casos lo siguen haciendo (Endere y Pedrotta, 2010; Pedrotta, 2013).

Son varias las experiencias junto a Directores de Cultura y a Directores de Museos que me permitieron construir un registro de los modos de acercamiento al patrimonio cultural desde las diferentes posiciones dentro del campo político, y en ciertos casos, con tensiones en el campo científico. A modo de ejemplificación, menciono una de mis primeras presentaciones desde el rol de "observador patrimonial" ante el entonces Director del Museo de Ciencias Naturales de Monte Hermoso, el Sr. Vicente Di Martino. Dim, como todos sus allegados lo llamaban y con quien posteriormente tuve el gusto de iniciar una amistad, resultó ser una persona fascinante, un apasionado por la paleontología y por la transmisión de sus saberes al público, en particular a los niños. Su primera reacción ante mi visita al Museo, luego de acordarla previamente por teléfono, fue la de sorpresa: - "no puedo creer que me vengas a ver tan pronto, yo pensé que era una promesa más de los de La Plata, y te soy sincero, pensé que no ibas a venir nunca". Para mí no era una obligación visitarlo en persona hasta que sucediera algo preciso, pero me resultaba distante establecer un diálogo de trabajo conjunto sin conocerlo mínimamente. Su modo de acercamiento al patrimonio cultural era de raíz científica, con la precisión y rigurosidad técnica de un geólogo o paleontólogo, pero también era desinteresada. Di Martino compartía el fervor de la investigación con colegas profesionales, pero a su vez se desligaba de la exposición académica y el roce de prestigio que conllevan las publicaciones, las citas, los debates públicos o los congresos. Como bien explica Bourdieu, "el campo [científico] produce esa forma particular de ilusión que es el interés científico, un interés que en comparación con las formas de interés que 
tienen vigencia corriente (en especial el campo económico) aparece como desinteresado, gratuito" (Bourdieu, 2008: 84). Su imaginario patrimonial me remitía al de los investigadores naturalistas del siglo XIX y principios del siglo XX, a los cuales mencionaba asiduamente en las campañas, como Ameghino, Holmberg, Moreno, y algunos científicos contemporáneos que para él mantenían ese fervor naturalista, ese fuego interno por el descubrimiento y por la intriga insaciable.

Junto a Di Martino compartí campañas de rescate paleontológico en el arroyo Chasicó y el Río Quequén Salado. En ambas locaciones pude presenciar la importancia de la pasión por descubrir y por la incertidumbre de lo inesperado para toda empresa científica. Aunque estas fueron mis primeras experiencias en campañas de paleontología, tenía la sensación de haber transitado cientos de veces estos arroyos y ríos que atesoran los misterios de la evolución de los mamíferos, los cambios climáticos, o los paisajes del pasado. Siempre las charlas terminaban en alguna barranca donde recordaba perfectamente qué fósil había encontrado, quien lo acompañaba, cómo los habían sacado, y donde habían ido a parar luego de su limpieza. Su pasión por la paleontología, arqueología, biología y los animales en general era emocionante; contagiaba la perseverancia por seguir conociendo, seguir explorando y nunca detenerse. El imaginario científico de Di Martino, puesto en práctica en su discursoimagen-texto, al caminar sobre la costa del río observando las barrancas, estimulaba a vivir ese escenario junto a él y vivenciar la experiencia de devenir paleontólogo por un día. No desde la postura academicista que piensa en el próximo artículo a publicar, sino como se mencionó anteriormente, desde la mirada del naturalista que se mueve al ritmo de sus emociones, de estar en el campo, en presencia de un objeto de estudio que se está por desvelar continuamente. Dim dejó el legado de una colección de fósiles formidable, con materiales de gran parte de la costa bonaerense, desde Mar del Plata hasta Chasicó, y un modo de transmitir la importancia de la paleontología a diversos tipos de públicos. Su vocación por la educación de los niños es uno de los ejemplos que ha dejado sembrado en la ciudad de Monte Hermoso y en la región, y su obra ha sido trascendental como antecedente para el proyecto actual de declarar Patrimonio Natural a la Reserva Natural Pehuecó-Monte Hermoso por parte de la UNESCO. El museo de Ciencias Naturales de Monte Hermoso, que fue armando desde su propia colección, es hoy uno de los mejores en la Provincia, visitado por miles de turistas en los veranos, siempre innovando en las muestras, los recursos interpretativos y el acercamiento a la gente. Este Museo lleva su nombre desde su fallecimiento en 2011, y es el reservorio de futuras investigaciones y publicaciones, las cuales nos darán con los años, la dimensión que tuvo su trayectoria y su interés por entender y preservar los misterios del pasado de nuestra región.

Otra experiencia relevante del trabajo en este Observatorio se dio ante el hallazgo y rescate de los fósiles de un glosotherium robustus ${ }^{2}$ en un camino vecinal cercano a la localidad de Saavedra (Figura 1). El aviso del descubrimiento fue hecho por un productor agropecuario que encontró los fósiles sobre el camino, luego de

${ }^{2}$ El glosotherium robustus es un perezoso gigante extinto, de América del Sur, llamado comúnmente "glosoterio" (Forasiepi \& Martinelli, 2007). 
pasar la máquina niveladora y dejar expuestos algunos huesos. Posteriormente a la prospección que realizamos junto a un técnico del Centro de Registro, se resolvió excavar el yacimiento y destinar los restos al museo local más cercano, en la localidad de Saavedra. Más allá de las vicisitudes técnicas que implicaron este rescate y que generaron confrontación de imaginarios científicos respecto al tratamiento de los fósiles — si debía avisarse a la comunidad paleontológica más cercana, si debía publicarse la información científica del rescate, quienes debían hacerlo-, fue interesante visualizar los diversos imaginarios patrimoniales que se contraponían entre las autoridades provinciales, las municipales, los docentes, periodistas locales, los técnicos encargados del rescate - incluyéndome - y los vecinos de la localidad.

Para las autoridades provinciales, este fósil era uno más de los tantos que aparecen anualmente en la Provincia, y por lo tanto no merecía ningún trato especial, ni tampoco debía ser publicado ni exhibido. En cambio, para los técnicos del mismo ente Provincial que tuvimos contacto con la comunidad local durante la excavación - vecinos, docentes, periodistas - , los fósiles eran sumamente importantes para instalar el tema de la preservación del patrimonio cultural y su valoración social en la zona. Las autoridades municipales resultaban contradichas entre ambas posturas y la tendencia laplatacentrista traía nuevos problemas locales, ante la dubitación sobre el destino final de los fósiles, ya que la comunidad partícipe se resistía a que nuevamente terminaran arrumbados en el Museo de Ciencias Naturales de La Plata y no en un museo local. Finalmente, luego de varias gestiones entre autoridades locales, medios de comunicación e integrantes de la comisión del Museo local, se acordó entre las partes dejar los fósiles en el Museo de Saavedra con la condición de reacondicionar la sala que albergara la muestra.

El proceso de divulgación del hallazgo fue lento, llevó más de un año, y finalizó con una muestra híbrida en todos los sentidos, con mezcla de otros materiales "importantes" para los funcionarios y técnicos del ente provincial, adosando una colección arqueológica del Museo que el mismo personal del Centro de Registro había catalogado varios años antes. La misma fue seleccionada para su exhibición con criterios estéticos de la museografía decimonónica, sin diseño gráfico e interpretativo, y con una mirada del hallazgo centrada en los escasos datos técnicos que se habían compilado del glosoterio, en detrimento de los valores sociales que el hallazgo movilizó entre múltiples actores de la comunidad, sin dejar lugar a la multivocalidad (Hodder, 2008).

Toda esta intervención provincial sobre la comunidad local dejó en claro que si se hubiese trabajado de forma inversa, dando voz y acción a las inquietudes emergentes de la Comisión de Amigos del Museo, docentes y técnicos en contacto directo con los actores, el resultado hubiese sido otro. La intervención tuvo como consecuencias el posicionamiento de un imaginario científico y patrimonial cristalizado en la voz oficial y unívoca del saber arqueológico de "la autoridad competente", basado en un conjunto de ideas incipientes sobre el patrimonio hallado y sobre su posible utilidad educativa en la comunidad local, como si el solo acto de instruir fuese suficiente para construir conocimiento. En ese sentido, se dictaron charlas de divulgación en los colegios de forma unilateral, sin relevar previamente el grado de 
conocimiento sobre el tema entre los alumnos y docentes, y sin dejar lugar a una construcción dialógica del hecho patrimonial y científico que había congregado a toda esta comunidad durante un año.

\section{Etnografía de imaginarios}

La discusión que plantea este trabajo sobre la identificación de los imaginarios patrimoniales, políticos y científicos, gira, en un plano subyacente, en torno a la escisión entre ciencia y política: entre el saber y el hacer, entre la producción y la reproducción de conocimiento, entre su génesis críptica y su trasposición a otros lenguajes. Asimismo, plantea el lugar de la antropología actual en torno a estas polaridades y la importancia de reflexionar sobre la práctica profesional-laboral vinculada a los diferentes modos de activación del patrimonio cultural (Prats, 2004), a la aplicación pragmática de las herramientas etnográficas (Escobar, 2000; Greenwood, 2000; Isla y Colmegna, 2005; Mastrangelo et al., 2013), así como también a la posición sociopolítica asumida por los diferentes actores sociales intervinientes (García Canclini, 2008; Hodder, 2008).

Se sostiene aquí que identificar imaginarios patrimoniales permite reconocer los intereses y motivaciones que existen en torno a un determinado recurso patrimonial, y por lo tanto poder diagnosticar posibles formas de intervención y comunicación entre quienes interactúan en la gestión del patrimonio en diferentes espacios sociales. En el estudio de estos dos casos, se analizaron las representaciones simbólicas del hallazgo, del manejo y de la difusión del patrimonio cultural como vía de acceso a los imaginarios que sostienen las prácticas y los discursos en torno al mismo. También se buscó contextualizar a estos imaginarios en el marco conceptual de los campos simbólicos y en particular en la intersección de los campos políticos y los científicos, incorporando al análisis enfoques teóricos claves como los de Bourdieu y Latour. El primero plantea que "los campos científicos son el ámbito de dos formas de poder correspondientes a dos especies de capital científico", que son el poder temporal o político, institucional y el poder específico, el prestigio personal (Bourdieu, 2008: 89). En tanto el segundo formula que "para comprender cabalmente las relaciones entre ciencias y política, primero hay que liberarse de las definiciones polémicas sobre la actividad científica" (Latour, 2012: 99). Tanto en el primero como en el segundo caso de estudio, las dificultades de los interlocutores para acordar el manejo del patrimonio cultural, tuvieron su origen en la confrontación de imaginarios sobre qué se debía hacer en cuanto a actividades científicas, y cómo se debía operar en los diferentes campos simbólicos - usualmente llamados "planos de acción"- de la gestión patrimonial: el político, el científico, el comunicativo, el educativo. Y particularmente sobre el campo científico, se pudieron reconocer en ambos casos las dos formas de poder señaladas por Bourdieu que irrumpen en los comportamientos individuales al interior de los grupos: el poder político institucionalizado — entes Provinciales, Municipios, Museos-y el poder específico del prestigio personal - funcionarios, técnicos, investigadores-.

En esta dirección, la relación dialéctica entre una etnografía de imaginarios que articula campos simbólicos intrincados en relaciones de poder, da sustento 
teórico-metodológico al estudio de la dimensión simbólica del patrimonio cultural, ya que ordena una vasta cantidad de información etnográfica y logra instrumentar un modelo de estudio, y de gestión patrimonial, que también puede ser aplicado a otros casos. Esto es factible si se considera a los imaginarios sociales como una red de significaciones múltiples que se manifiestan en los campos simbólicos que les dan su origen, a la vez que son atravesados por los mismos y extienden sus alcances extralimitando cada campo, sea político, científico, patrimonial, económico u otro. Esta decodificación del entramado de significaciones en red nos permite visualizar, de forma integral, la posición que ocupan los actores sociales dentro de los campos que los interpelan, a la vez que nos ofrece pautas sobre cómo abordar el proceso de intercomunicación entre los grupos sociales y sus intereses parciales.

Ahora bien, también nos lleva a formular nuevas preguntas en el plano de la acción, de la gestión antropológica, y de la investigación-acción como la denomina Greenwood (2000): ¿Cómo se abordan estos entramados de imaginarios? ¿Quiénes deben y pueden hacerlo? ¿Cuáles son las etapas de un trabajo integral que considere los imaginarios de los actores sociales en torno a una activación patrimonial? ¿Cómo es factible articular la investigación de imaginarios, el trabajo de campo, la gestión cultural y sus implicancias políticas? Desde una mirada antropológica enfocada en una etnografía de imaginarios sociales, todo hecho social es factible de ser analizado sistemáticamente, siguiendo un método de estudio que permita interpretar sus componentes socioculturales, y desde allí construir modelos teóricosexperimentales que den cuentan de la materia simbólica y material sobre la que se sustentan las acciones de sujetos y grupos sociales. Asimismo, la aplicación de esta práctica etnográfica en diversos espacios sociales, no debe restringirse a situaciones de lejanía espacial, de extrañeza o exotismo (Clifford, 1999: 77), ya que puede ser practicada, experimentada, al interior de la sociedad del antropólogo y en ámbitos en los cuales el mismo, en ciertos casos, es un actor activo y sujeto de autorreflexión (Latour, 2007; Iparraguirre, 2011). Recapitulando entonces la tradición de la antropología simbólica mencionada al inicio del trabajo, junto con la visión actual de la crítica etnográfica, puede enfatizarse que los lugares de campo y el reconocimiento de los imaginarios que los definen, están imbricados en la práctica etnográfica: "Existe una relación dialéctica clave entre los lugares donde trabajamos y la clase de sujetos que dicha práctica produce" (Wright, 2005: 55).

En esta dirección, se sostiene que la etnografía permite un acceso de primera mano a las representaciones sociales de los actores intervinientes en una activación patrimonial tangible o intangible (Prats, 2004; Santamarina Campos, 2013), y esto a su vez debe ser nutrido con enfoques complementarios, como la multivocalidad (Hodder, 2008), la memoria patrimonial (Tedesco, 2004), y la arqueología simétrica ya mencionada (González-Ruibal, 2007). Precisamente, respecto a casos de patrimonio arqueológico como el que se analizó, Hodder plantea que los arqueólogos tienen la responsabilidad moral y ética de facilitar la participación de todos los grupos e individuos al momento de interpretar un sitio. La multivocalidad, en este sentido, es un modo de dar poder a los grupos marginales proveyéndolos de un escenario desde el cual puedan expresarse; implica un cambio radical de todos 
los niveles de la práctica arqueológica, desde el diseño de la investigación, los métodos de escritura, las publicaciones y el modo de presentar el pasado; no es solo el producto de un argumento teórico, sino el resultado de una hibridación sociopolítica e intelectual (Hodder, 2008: 196). En concordancia también con el planteo de la investigación-acción formulado por Greenwood, es prioritario que una investigación social como la que aquí se propone, sea "desarrollada mediante una colaboración entre un investigador profesional y los "dueños del problema" en una organización local, una comunidad o un grupo intencional creado para un propósito específico" (Greenwood, 2000: 32).

Asimismo, el ejercicio de una etnografía de imaginarios abierta a incorporar prácticas investigativas como la multivocalidad y la investigación-acción, permite construir una noción de patrimonio social que trasciende a los funcionarios e investigadores de turno, y que demanda implementar nuevas políticas de investigación y preservación que integren los imaginarios patrimoniales de los pobladores locales. Esto es prioritario al momento de diseñar y ejercer políticas del manejo patrimonial, de acuerdo a que "toda política cultural es una política con los imaginarios que nos hacen creer semejantes" (García Canclini, 2008: 107). Es decir, en primer término, la política cultural debe incluir a toda forma de política, no solo aquella que dice algo sobre la cultura, sino a la política en sí, al acto de representar y ser representando. A su vez, si la cultura como totalidad es la forma primera de la re-presentación entre sujetos, su praxis política debe dar cuenta de la dinámica de identificación entre los grupos, ya sea por su diferenciación con los otros, o los que no son uno, o como uno. Así, gestionar esta política con los imaginarios-otros, es gestionar la diferencia y la semejanza, la cercanía y la lejanía - como gustaba señalarlo Lévi-Strauss (1968). García Canclini completa su idea con un factor clave:

\begin{abstract}
Al mismo tiempo, es una política con lo que no podemos imaginar de los otros, para ver si es posible compatibilizar las diferencias: como convivir con los que no hablan correctamente mi lengua, [que] permiten que las mujeres no tengan velo (o lo tengan), [que] no aceptan los valores de la religión hegemónica o de la racionalidad científica, [que] rechazan las jerarquías o pretenden subsumirlas en la horizontalidad democrática (García Canclini, 2008:107).
\end{abstract}

Lo que no podemos imaginar de los otros, se llega a completar igual: con la creencia en la semejanza, con los matices de acercamiento, con la semántica estadística que re-construye al otro en pedazos proporcionales, en mitades promediadas, en aproximaciones tangenciales a eso que se cree que el otro es. Lo narra de forma precisa el autor al afirmar que se trata de una política con los imaginarios, y no con las personas, con los partidos políticos, o con las instituciones. La política cultural se da, se concibe y se practica desde los imaginarios, a través de su materia simbólica o imaginativa, y por esto es clave saber reconocerlos y ponerlos en comunicación participativa.

En el caso del concepto memoria patrimonial formulado por Tedesco, su noción puede complementarse directamente con la de imaginario patrimonial ya que "la memoria colectiva tiende a estar en consonancia con un conjunto de 
representaciones de formas temporales que cada grupo social produce, institucionaliza, practica y transmite por medio de diferentes formas de socialización" (Tedesco, 2004: 74). Asimismo, asocia la importancia de considerar los imaginarios populares en el estudio del patrimonio, y cómo a través de la memoria patrimonial es posible acercarse a la construcción imaginaria de lo social (Tedesco, 2004: 86), aspecto central de todo trabajo etnográfico que pretenda acercarse a la realidad cotidiana de los interlocutores. En esta perspectiva, pueden sumarse también estudios complementarios enfocados a la revalorización local y los usos turísticos del patrimonio cultural y natural, como los efectuados en localidades próximas a la región de estudio (Endere et al., 2009: 315), así como aquellos que ponen el acento en la relevancia de los procesos de patrimonialización de la naturaleza (Almiron, Bertoncello y Troncoso, 2006; Carbonell, 2010; Santamarina Campos, 2012).

En definitiva, la hipótesis que ha guiado silenciosamente a este trabajo postula que la ineficiencia o fracaso de la implementación de prácticas científicas y políticas de manejo, de investigación y de difusión en torno al patrimonio cultural, responde entre otros factores, al desconocimiento de los imaginarios patrimoniales, políticos y científicos que existen entre todos los grupos sociales involucrados al momento de dar significados y sentidos a los recursos, así como en las instancias de toma de decisiones. Asimismo, estos otros factores pueden ser internalizados por los actores en las situaciones de "negociación" y disputa de intereses, si se aplica el concepto de demarcación entre ciencias por un lado y políticas por el otro (Latour, 2012: 157). El autor explica que para trascender la dicotomía que sigue dividiendo a los científicos de los políticos, es necesario pensar y discutir en conjunto las controversias - en este caso patrimoniales —, en lugar de seguir tratándolas por separado, reproduciendo este factor de separabilidad que aboca a una in-comunicación de los grupos en permanente controversia, y en permanente demarcación de los ámbitos de incumbencia de unos y otros.

\section{Modelo de intervención}

A modo de conclusión y como propuesta teórica-metodológica, se plantea que es indispensable realizar estudios etnográficos en la comunidad local partícipe de una activación patrimonial, integrando en la práctica etnográfica el mapeo, la cartografía de los imaginarios de las autoridades políticas involucradas, así como los de la comunidad científica interviniente. Esto posibilita tener en claro cuáles son los imaginarios en tensión de todos estos actores, para contar con herramientas precisas al momento de intervenir, y que puedan ser aplicadas junto a las metodologías necesarias para cada fase del proceso - ya sean arqueológicas, paleontológicas, de rescate, de manejo, de conservación, de divulgación, la redacción de ordenanzas, la firma de convenios interinstitucionales - entre otros (Figura 2).

La Figura 2 presenta el esquema preliminar de un modelo de intervención, basado en el desarrollo teórico y la experiencia en el campo aquí presentado. Partiendo de la inquietud inicial de gestionar e investigar patrimonio cultural entre diferentes grupos sociales que se ubican en diferentes posiciones de poder dentro del espacio social implicado, el modelo propone delinear los modos de intervención luego de 


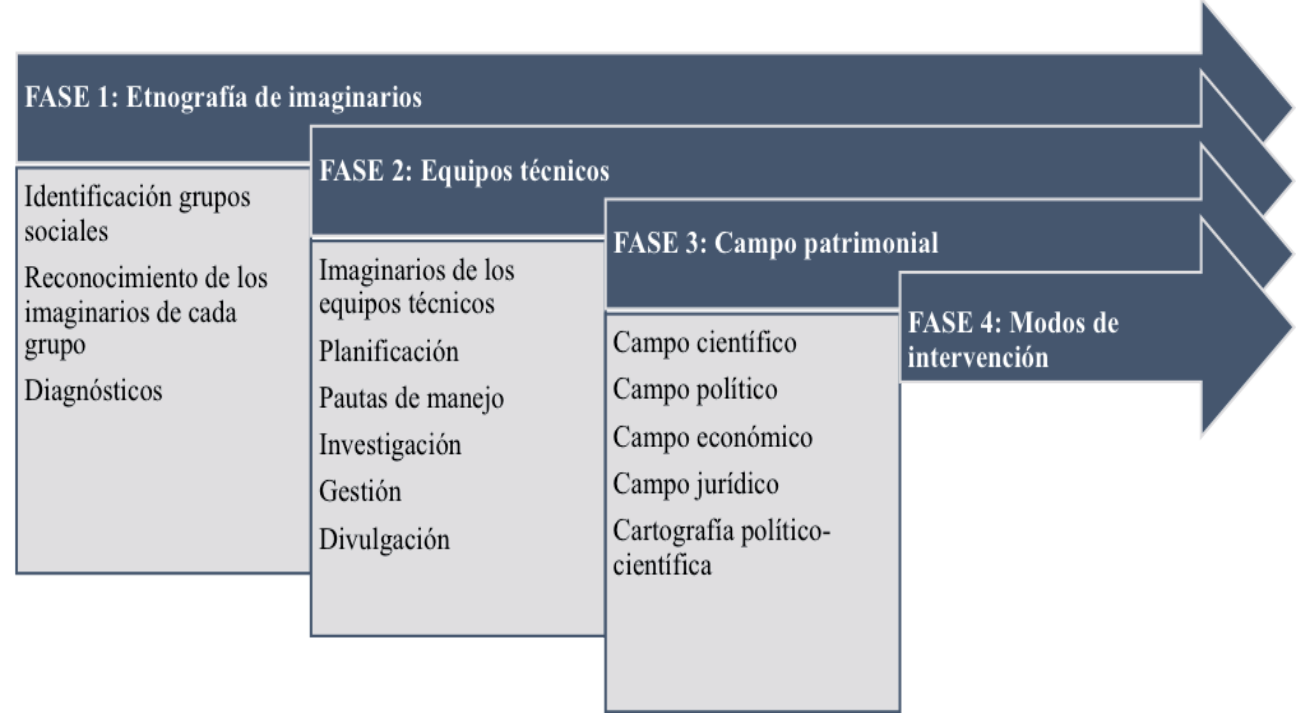

Figura 2. Esquema de un modelo de intervención en el manejo del patrimonio cultural.

construir y sistematizar el campo patrimonial, que previamente requiere del reconocimiento de los imaginarios sociales entre los grupos sociales. De este modo, el proceso de intervención en una activación patrimonial en un territorio específico, requiere de cuatro fases que se inician de forma secuencial, aunque todas permanecen activas hasta la finalización del mismo ${ }^{3}$. La fase 1 implica el trabajo etnográfico sobre los imaginarios de los grupos y actores intervinientes, que permita ir identificando y diagnosticando a los grupos sociales, a la vez que se trabaja, en la fase 2, junto a los equipos técnicos en instancias de planificación, investigación, manejo y divulgación ${ }^{4}$. La fase 3 activa el reconocimiento y la lectura sincrónica de los campos simbólicos que interpelan la praxis de cada actividad de las fases previas - campo científico, político, económico y jurídico-, todos los cuales pueden ser analizados desde la perspectiva de los imaginarios para dar una referencia concreta de cómo se construye, a la par de todo el proceso empírico, el campo patrimonial que opera en el plano simbólico de todos los grupos sociales afectados al proceso. Finalmente, la fase 4 contiene los modos de intervención que necesariamente deben ser el resultado de la puesta en acción de las tres fases previas, aplicados como ya se mencionó, a la activación patrimonial en cuestión, y en un territorio específico.

${ }^{3}$ La dinámica de interpretación del modelo se lee simultáneamente hacía abajo y hacia la derecha para cada una de las fases. Su visualización gráfica puede asociarse a la lectura de una partitura musical de varias voces o instrumentos, o bien a la interfase de edición de video y música en un programa informático con varios canales o pistas.

${ }^{4}$ En los casos de rescate urgente, como el descubrimiento de yacimientos a cielo abierto o hallazgos espontáneos por fenómenos climáticos, es prioritario intervenir con medidas de seguridad inmediatas para la preservación de los recursos hasta la puesta en práctica de la fase 1. 
Como ya lo dijera Greenwood hace varios años, la "validez" de estos resultados se deben confirmar en la acción, y no "a través de la aprobación de colegas académicos" (2000: 47). Estos modos de intervención, son las respuestas en la toma de decisiones y las soluciones técnicas operativas que el modelo debe poder explicitar con miras a un manejo eficiente, sustentable y multivocal del patrimonio cultural.

\section{Referencias bibliográficas}

ALMIRON, Analía; BERTONCELLO, Rodolfo; TRONCOSO, Claudia

2006 "Turismo, patrimonio y territorio. Una discusión de sus relaciones a partir de casos de Argentina", Estudios y Perspectivas en Turismo, 15, (2): 101-124.

APPADURAI, Arjun

2001 La modernidad desbordada. Dimensiones culturales de la globalización. Buenos Aires: Fondo de Cultura Económica.

BACZKO, Bronislaw

2005 Los imaginarios sociales. Memorias y esperanzas colectivas. Buenos Aires: Nueva Visión.

BOAS, Franz

1964 [1911] Cuestiones fundamentales de antropología cultural. Buenos Aires: Ediciones Solar Hachetté.

BOURDIEU, Pierre

2008 Los usos sociales de la ciencia. Buenos Aires: Nueva Visión.

CARBONELL, Eliseu.

2010 "La patrimonialización de un paisaje marítimo: de la arena de la playa a la arena política", Pasos. Revista de turismo y patrimonio cultural, 8, (4): 569-581.

CASTORIADIS, Cornelius

1999 La institución imaginaria de la sociedad. Buenos Aires: Tusquets.

CLIFFORD, James

1999 Itinerarios Culturales. Barcelona: Gedisa.

CERTEAU, Michel de

1984 The Practice of Everyday Life. Berkeley: University of California Press.

DURAND, Gilbert

2000 La imaginación simbólica. Buenos Aires: Amorrortu.

2003 Mitos y sociedades: introducción a la mitodología. Buenos Aires: Biblos.

2004. Las estructuras antropológicas del imaginario. México: Fondo de Cultura Económica.

DURKHEIM, Emile

1982 [1912] Las formas elementales de la vida religiosa. Madrid: Akal. 
ENDERE, María Luz

2009 “Algunas reflexiones acerca del patrimonio", en M. L. Endere y J. Prado (Eds.), Patrimonio, Ciencia y Comunidad. Su abordaje en los Partidos de Azul, Tandil y Olavarría, Olavarria: UNICEN y Municipalidad de Olavarría: 17-45.

ENDERE, María Luz; PEDROTTA, Victoria

2010 “Para qué hace falta una ley? Venturas y desventuras de un anteproyecto de ley para la provincia de Buenos Aires", en M. Berón, L. Luna, M. Bonomo, C. Montalvo, C. Aranda y M. Carrera Aizpitarte (Eds.), Mamül Mapu: Pasado y Presente desde la Arqueología Pampeana, Tomo I, Ayacucho: Editorial Libros del Espinillo, 445-470.

ENDERE, María Luz; CHAPARRO, María Gabriela; PALAVECINO, Valeria.; et al.

2009 "Percepciones y reflexiones sobre el patrimonio de los partidos de Azul, Olavarría y Tandil”, en M. L. Endere y J. Prado (Eds.), Patrimonio, ciencia y comunidad. Su abordaje en los partidos de Azul, Tandil y Olavarría, Olavarria: UNICEN y Municipalidad de Olavarría: 315-332.

ESCOBAR, Arturo

2000 "El lugar de la naturaleza y la naturaleza del lugar:¿ globalización o postdesarrollo?", en Arturo Escobar (Ed.), La colonialidad del saber: eurocentrismo y ciencias sociales. Perspectivas latinoamericanas, Buenos Aires: Clacso, 113-143.

FORASIEPI, Analía; MARTINELLI, Agustín

2007 Bestiario fósil: mamíferos del pleistoceno de la Argentina. Buenos Aires: Albatros.

FIORI, Sandra; SCOROLLI, Alberto; ZALBA Sergio

1997 Propuesta de Plan de Manejo del Parque Provincial Ernesto Tornquist. GEKKOGrupo de Estudios en Conservación y Manejo, Universidad Nacional del Sur.

GARCÍA CANCLINI, Néstor

1999 "Los usos sociales del patrimonio cultural", en E. Aguilar Criado (Ed.), Patrimonio etnológico: nuevas perspectivas, Granada: Instituto Andaluz del Patrimonio Histórico: 16-33.

2008 La globalización imaginada. Buenos Aires: Paidos.

GONZÁLEZ-RUIBAL, Alfredo

2007 “Arqueología Simétrica: Un giro teórico sin revolución paradigmática", Complutum, 18: 283-319.

GREENWOOD, Davydd J.

2000 "De la observación a la investigación-acción participativa: una visión crítica de las prácticas antropológicas”, Revista de Antropología Social, 9: 27-49.

HODDER, Ian

2008 "Multivocality and Social Archaeology", en J. Habu, C. Fawcett y J. Matsunaga (Eds.), Evaluating Multiple Narratives Beyond Nationalist, Colonialist, Imperialist Archaeologies. Nueva York: Springer, NuevaYork, 196-200. 
HUBERT, Henry

1990 [1901] "Estudio sumario sobre la representación del tiempo en la religión y la magia", Reis, 51: 177-204.

\section{ICOMOS}

1990 Carta para la protección y manejo del patrimonio arqueológico.

1999 Carta Internacional sobre Turismo Cultural. La Gestión del Turismo en los sitios con Patrimonio Significativo. Adoptada por ICOMOS en la $12^{\mathrm{a}}$ Asamblea General en México, octubre de 1999.

2005 Carta de Enamel para la Interpretación de Lugares pertenecientes para el Patrimonio Cultural. http://www.international.icomos.org

IPARRAGUIRRE, Gonzalo

2007 Investigación sobre el Manejo de Recursos Culturales en el Parque Provincial Ernesto Tornquist. Informe técnico editado para las autoridades del Parque Tornquist.

2011 "Ciencia, imaginarios y comunicación en torno al Parque Provincial E. Tornquist", en Actas del X Congreso Argentino de Antropología Social. La antropología interpelada: nuevas configuraciones político-culturales en América latina. Buenos Aires: Editorial de la Facultad de Filosofía y Letras, Universidad de Buenos Aires.

IPARRAGUIRRE, Gonzalo; ALGRAIN, Mariana; MENÉNDEZ, Lumila

2010 "Observatorios de patrimonio arqueológico y paleontológico en la provincia de Buenos Aires", en M. Berón, L. Luna, M. Bonomo, C. Montalvo, C. Aranda y M. Carrera Aizpitarte (Eds.), Mamül Mapu: Pasado y Presente desde la Arqueología Pampeana, Tomo I, Ayacucho: Editorial Libros del Espinillo, 481-488.

ISLA, Alejandro; COLMEGNA, Paula

2005 Política y poder en los procesos de desarrollo: debate y posturas en torno a la aplicación de la antropología. Buenos Aires: De las Ciencias.

LATOUR, Bruno

2007 Nunca fuimos modernos. Ensayo de antropología simétrica. Buenos Aires: Siglo Veintiuno Editores.

2012 Cogitamus. Seis cartas sobre las humanidades cientificas. Buenos Aires: Paidos,

LÉVI-STRAUSS, Claude

1968 De cerca y de lejos. Córdoba: Ediciones Pasado y Presente.

1984 Antropología Estructural. Buenos Aires: Eudeba.

MASTRANGELO, Andrea; DÍAZ GALÁN, Laura; CAROLINA, Planes; RODRÍGUEZ, María Paula

2013 “Antropologías aplicadas varias: una revisión desde la praxis", Publicar, 16: .47-70.

MAUSS, Marcel

1979 [1905] "Ensayo sobre las variaciones estacionales en las sociedades esquimales. Un estudio de morfología social”, en M. Mauss, Sociología y Antropología: 359-431. Madrid: Tecnos. 
MOLINARI, Roberto

1998 "Orientaciones para la gestión y supervivencia de los recursos culturales: Proyecto de Reglamento para la Preservación del Patrimonio Cultural en Areas Protegidas de la APN", en I Congreso Virtual de Antropología y Arqueología. http://www.naya. org.ar/congreso/ponencia3-8.htm

2000 "Rumbo a lo conocido: causas, condiciones y consecuencias en la difusión de sitios arqueológicos”, en Desde el país de los gigantes: perspectivas arqueológicas en Patagonia. Río Gallegos: Universidad Nacional de la Patagonia Austral: 635-649.

OEA

1976 Convención de San Salvador sobre Defensa del Patrimonio Arqueológico, Histórico y Artístico de las Naciones Americanas.

PRATS, Llorenc

2004 Antropología y patrimonio. Barcelona: Ariel.

2011 "La viabilidad turística del patrimonio", Pasos. Revista de turismo y patrimonio cultural, 9, $\mathrm{n}^{\circ}$ 2: 249-264.

PEDROTTA, Victoria

2013 "Reducción jesuítica Nuestra Señora de la Concepción de los Indios Pampas (Castelli, Pcia. de Buenos Aires): crónicas de una década de reclamos e inacción". Revista del Museo De La Plata, sección antropología, 13 (87): 2-16.

RICOEUR, Paul

2012 Ideología y utopía. Barcelona: Gedisa.

SANTAMARINA CAMPOS, Beatriz

2012 "Patrimonialización de la naturaleza en la comunidad valenciana. Espacios, ironías y contradicciones", en Oriol Beltran, José J. Pascual y Ismael Vaccaro, Patrimonialización de la naturaleza. El marco social de las políticas ambientales, San Sebastián: Ankulegi Antropologia Elkartea: 27-44.

2013 "Los mapas geopolíticos de la Unesco: entre la distinción y la diferencia estan las asimetrias. El exito (exótico) del patrimonio inmaterial", Revista de Antropología Social, 22: 263-286.

TEDESCO, Juan Carlos

2004 Nas cercanias da memória. Temporalidade, experiência e narração. Universidade de Passo Fundo: Editora Universitária.

\section{UNESCO}

1972 Convención sobre la Protección del Patrimonio Mundial Natural y Cultural, adoptada por la Conferencia General de la UNESCO en la $17^{\circ}$ reunión celebrada en París el 16-11-72. http://www.unesco.org

2003 Convención para la protección del patrimonio intangible. http://www.unesco.org

2006 Textos básicos de la convención del patrimonio mundial de 1972. UNESCO, París.

WRIGHT, Pablo

2005 "Cuerpos y espacio plurales: sobre la razón espacial de la práctica etnográfica", Indiana Berlin 22: 55-74. 
2012 “Trabajo de campo en el tiempo: los lugares etnográficos de la antropología de la historia", Memoria Americana 20 (1): 35-181.

WRIGHT, Pablo; CERIANI CERNADAS, César

2007 “Antropología simbólica: pasado y presente", Relaciones de la Sociedad Argentina de Antropología, Vol. XXXII: 319-348.

WUNENBURGER, Jean Jaques

2008 Antropología del imaginario. Buenos Aires: Del Sol. 